Tropical Journal of Pharmaceutical Research December 2014; 13 (12): 1993-1997

ISSN: $1596-5996$ (print); 1596-9827 (electronic)

(C) Pharmacotherapy Group, Faculty of Pharmacy, University of Benin, Benin City, 300001 Nigeria.

All rights reserved.

Available online at http://www.tjpr.org

Original Research Article

http://dx.doi.org/10.4314/tjpr.v13i12.6

\title{
Effect of Triptolide on Functions of Monocytes/ Macrophages in Mildly Acid Microenvironment
}

\author{
Hongchao Feng ${ }^{1,2}$, Yufeng Song ${ }^{1 *}$, Hong Ma ${ }^{1}$, Yubo Zhang ${ }^{1}$ and Benyuan Mao ${ }^{2}$ \\ ${ }^{1}$ College of Stomatology, Guiyang Medical University, ${ }^{2}$ Guiyang Stomatological Hospital, Guiyang, Guizhou 550004, PR China
}

*For correspondence: Email: songyufengdoc@126.com

Received: 7 June 2014

Revised accepted: 12 November 2014

\begin{abstract}
Purpose: To investigate the effects of triptolide (TP) on the proliferation of monocytes/macrophages, secretion of vascular endothelial growth factor (VEGF) and vascular endothelial growth factor-C (VEGFC) in mildly acid microenvironment.

Methods: Human monocytes/macrophage system (THP-1 strains) was cultured under acid (pH 6.6 and $\mathrm{pH}$ 6.8) microenvironment and normal microenvironment $(\mathrm{pH}$ 7.2) containing different concentrations of $\operatorname{TP}(5,10,20$ and $50 \mu \mathrm{g} / \mathrm{mL})$ for 24, 48 and $72 \mathrm{~h}$. The number of monocytes/macrophages under the varying conditions was subsequently determined by methyl thiazolyl tetrazolium (MTT) assay. The supernatants were collected after 24- $h$ culture, and the content of VEGF and VEGF-C in each supernatant measured by enzyme-linked immunosorbent assay (ELISA).

Results: The proliferation of monocytes/macrophages to some extent enhanced in mildly acid microenvironment. The content of VEGF and VEGF-C declined gradually with increasing TP concentration at the same $\mathrm{pH}$ value, and reached a minimum at $50 \mathrm{ug} / \mathrm{mL}$ and $\mathrm{pH} 6.6$.

Conclusion: In mildly acid microenvironment, TP promotes the proliferation of monocytes/macrophages to some extent and can reduce their ability to secrete tumor growth promoting factors.
\end{abstract}

Keywords: Monocytes, Macrophages, Triptolide, Vascular endothelial growth factor, Tumor growth, Tripterygium wilfordii, Sub-acid microenvironment

Tropical Journal of Pharmaceutical Research is indexed by Science Citation Index (SciSearch), Scopus, International Pharmaceutical Abstract, Chemical Abstracts, Embase, Index Copernicus, EBSCO, African Index Medicus, JournalSeek, Journal Citation Reports/Science Edition, Directory of Open Access Journals (DOAJ), African Journal Online, Bioline International, Open-J-Gate and Pharmacy Abstracts

\section{INTRODUCTION}

Tumor growth is a complicated process, in which many factors participate. The interaction between tumor cells and tumor stroma has been reported to play an important role in tumor growth [1]. Tripterygium wilfordii is a perennial vine belonging to the Celastraceae family. Its active ingredients exist mainly in the roots. It has been used as a traditional Chinese medicine for nearly 2000 years. TP is one of the active ingredients of Tripterygium wilfordii. It is suggested that TP has biological activity such as immunosuppression, anti-inflammatory effect, anti-fertility effect and anti-tumor effect [2,3]. TP can suppress the activities and induce apoptosis of many kinds of tumor cells $[2,3]$. TP also has an inhibitory effect on tumor angiogenesis [4] and a strong immunomodulatory effect, including modulation of the macrophagocyte function [5]. So far, no studies have been carried out to investigate whether TP has a modulation effect on monocyte/macrophage in mildly acid microenvironment currently.

Mononuclear macrophages that infiltrate tumor tissues are mainly M2 phenotype $[6,7]$. These participate in the process of tumor infiltration, 
growth and metastasis by secreting many factors which promote vascular and lymphatic growth such as VEGF and VEGF-C [8-10].

In this study, the effect of TP on the proliferation and function of monocytes/macrophages in mildly acid microenvironment was investigated in in vitro experiments, with a view to providing more experimental data for developing anti-tumor drugs from Tripterygium wilfordii Hook.

\section{EXPERIMENTAL}

\section{Specimen}

Monocytes/macrophages: THP-1 was purchased from Key Laboratory of Transplant Engineering and Immunology of Health Ministry of China, West China Hospital, Sichuan University.

\section{Reagents}

Human VEGF (vascular endothelial growth factor) (PeproTech, USA), VEGF-C ELISA Kit (Eton Bioscience, USA), double antibody (Eton Bioscience, USA), MTT (AMRESCO, USA), FBS (hyclone, USA), RPMI-1640 medium (Life Technologies, China), TP (Sigma, USA), and dimethyl sulfoxide(DMSO) (Beijing reagent factory) were used in this study.

\section{Preparation of TP-containing Roswell Park Memorial Institute (RPMI)-1640)}

TP was dissolved in $10 \mathrm{ml}$ DMSO to prepare 1 $\mathrm{mg} / \mathrm{mL}$ stock solution. The mother liquor was filtered and repackaged into $1 \mathrm{~mL}$ vial, and stored under $-20{ }^{\circ} \mathrm{C}$ for use. Before starting the experiment, TP mother liquor was added to RPMI-1640 complete media containing $2 \%$ FBS separately and the concentration was adjusted into $0,5,10,20$ and $50 \mu \mathrm{g} / \mathrm{mL}$, and $\mathrm{pH}$ was adjusted to $6.6,6.8$ and 7.2 with $5.5 \% \mathrm{NaHCO}_{3}$ and $1 \mathrm{~N} \mathrm{HCl}$.

\section{Preparation of TP cell suspensions}

THP-1 cells were cultured and passaged according to the instructions from Key Laboratory in Transplant Engineering and Immunology of Chinese Health Ministry, and re-suspended in RPMI-1640 containing $2 \%$ FBS. The number of cells was counted and adjusted to $2 \times 10^{5}$ cells/mL.

THP-1 cells were inoculated in a 96-well plate (100 $\mu \mathrm{L}$ well), and $200 \mu \mathrm{L}$ maintenance media with TP at concentrations of $0,5,10,20$ and 50 $\mu \mathrm{g} / \mathrm{mL}$. Three wells were set for each TP concentration. The plates were incubated at 37
${ }^{\circ} \mathrm{C}, 5 \% \mathrm{CO}_{2}$ and saturated humidity in an incubator for 24,48 and $72 \mathrm{~h}$. About $20 \mu \mathrm{L}$ of 5 $\mathrm{mg} / \mathrm{mL}$ MTT was added into each well 4 hours before end of the incubation, and then the plate was incubated at the same conditions. After incubation, the culture was centrifuged at $6000 \mathrm{~g}$ for $5 \mathrm{~min}$, and the supernatant was carefully discarded. DMSO was added into each well, and the absorbance of each well was measured at $490 \mathrm{~nm}$ using a microplate reader.

\section{Detection of VEGF and VEGF-C}

One hundred microliters of the solution of resuspended THP-1 cells and $100 \mu \mathrm{L}$ cell culture medium at each $\mathrm{pH}$ value was added to each well to make the concentration of monocytes/macrophages $2 \times 10^{6} / \mathrm{mL}$. The concentration gradients of TP were set as 0,5 , 10,20 and $50 \mu \mathrm{g} / \mathrm{mL}$. The plates were incubated in the solutions with $\mathrm{pH} 6.6,6.8$ and 7.2 at $37{ }^{\circ} \mathrm{C}$ in a $5 \% \mathrm{CO}_{2}$ incubator for $24 \mathrm{~h}$. The supernatant was collected and the amounts of VEGF and VEGF-C in the supernatant were determined by ELISA. Three wells were set for every single concentration. The operations were performed strictly according to the instructions of VEGF-C ELISA Kit from the manufacturer (Eton Bioscience, USA).

\section{Statistical analysis}

The contents of VEGF and VEGF-C in supernatant are presented as means \pm standard deviation (SD). Data from MTT assays were analyzed with analysis of variance of orthogonal design, while the OD values were presented as (means \pm SD). Statistical analysis was performed using SPSS 13.0. $P<0.05$ was considered statistically significant.

\section{RESULTS}

\section{Effects of TP on the proliferation of THP-1 cells}

As shown in Table 1, the number of THP-1 cells had an increasing tendency with an increased TP concentration at the same $\mathrm{pH}$ and action time, and the number decreased at concentration of 50 $\mu \mathrm{g} / \mathrm{mL}$. Significant difference was found among different concentrations $(p<0.05)$. Cell number showed with prolonging culture time and decreased significantly at $72 \mathrm{~h}(p<0.01)$. With the increase of $\mathrm{pH}$, the number of cells increased gradually ( $\mathrm{pH} 6.6$ and 6.8) and then declined, and there was a statistical difference among groups $(p<0.01)$. The cell number increased markedly at $48 \mathrm{~h}$ (Table 1$)$.

Trop J Pharm Res, December 2014; 13(12): 1994 
Effect of TP concentration and pH on VEGF and VEGF-C

The content of VEGF and VEGF-C declined gradually with the increasing TP concentration at the same $\mathrm{pH}$ value, and reached the minimum at $50 \mathrm{ug} / \mathrm{mL}$ and $\mathrm{pH} 6.6$ (Table 2 and 3).

\section{DISCUSSION}

The extracellular microenvironment of solid tumors is acidic ( $\mathrm{pH} 6.5-6.9)$, which is lower than the $\mathrm{pH}$ value for normal cells $(7.2-7.5)$ [11]. The functional vasculature of tumors is often inadequate to supply the nutritional needs of the expanding population of tumor cells, leading to deficiency of oxygen and many other nutrients. The production of lactic acid under anaerobic conditions and the hydrolysis of ATP in an energy-deficient environment contribute to the acidic microenvironment which has been found in many types of tumor [12]. With increase in tumor size, blood supply to the inner part of tumors is compromised, so local hypoxia and high lactic acid microenvironment are common for many tumors. Even in the condition with full oxygen supply, tumor cells generate energy by glycolysis and produce a lot of $\mathrm{H}^{+}$and lactic acid. Meanwhile, poor local blood supply induced by the infinite proliferation of tumor cells also causes the acid extracellular microenvironment of the tumor tissues because of high lactic acid level [13]. The extracellular $\mathrm{pH}(\mathrm{pHe})$ of tumor tissues is often acidic, and acidic metabolites, e.g., lactic acid caused by anaerobic glycolysis in hypoxia, seem to be the main cause. In consequence, $\mathrm{pH}$ 6.6 and 6.8 were used as experimental group to present the mildly acid microenvironment of tumor tissues, and $\mathrm{pH} 7.2$ was taken as control group in our study.

Table 1: Effect of TP concentration and time on the proliferation of THP-1 cells

\begin{tabular}{ccccccc}
\hline \multirow{2}{*}{ Time (h) } & $\mathbf{p H}$ & \multicolumn{7}{c}{ TP concentration $(\boldsymbol{\mu g} / \mathbf{m L})$} \\
\cline { 2 - 6 } & & $\mathbf{0}$ & $\mathbf{5}$ & $\mathbf{1 0}$ & $\mathbf{2 0}$ & $\mathbf{5 0}$ \\
\hline \multirow{2}{*}{24} & 6.6 & $0.23 \pm 0.01$ & $0.27 \pm 0.06$ & $0.41 \pm 0.03$ & $0.46 \pm 0.02$ & $0.36 \pm 0.06$ \\
& 6.8 & $0.33 \pm 0.00$ & $0.33 \pm 0.0$ & $0.36 \pm 0.01$ & $0.32 \pm 0.00$ & $0.25 \pm 0.05$ \\
& 7.2 & $0.55 \pm 0.00$ & $0.57 \pm 0.00$ & $0.60 \pm 0.02$ & $0.60 \pm 0.01$ & $0.44 \pm 0.01$ \\
48 & 6.6 & $0.21+0.03$ & $0.57 \pm 0.00$ & $0.69 \pm 0.01$ & $0.95 \pm 0.01$ & $1.16 \pm 0.00$ \\
& 6.8 & $0.99 \pm 0.00$ & $0.25 \pm 0.01$ & $0.34 \pm 0.00$ & $0.35 \pm 0.04$ & $0.37 \pm 0.01$ \\
& 7.2 & $1.98 \pm 0.04$ & $2.45 \pm 0.00$ & $2.46 \pm 0.00$ & $2.50 \pm 0.01$ & $1.13 \pm 0.00$ \\
& 6.6 & $0.53 \pm 0.00$ & $0.57 \pm 0.00$ & $0.50 \pm 0.02$ & $0.58 \pm 0.01$ & $0.68 \pm 0.01$ \\
& 6.8 & $0.24 \pm 0.00$ & $1.33 \pm 0.00$ & $1.36 \pm 0.01$ & $0.88 \pm 0.00$ & $0.76 \pm 0.01$ \\
& 7.2 & $0.23 \pm 0.00$ & $0.22 \pm 0.00$ & $0.23 \pm 0.00$ & $0.25 \pm 0.00$ & $0.16 \pm 0.00$ \\
\hline
\end{tabular}

$T P=$ triptolide; values are mean $\pm S D(n=3)$

Table 2: Content of VEGF (ug/mL) at different TP concentrations and $\mathrm{pH}$

\begin{tabular}{lcccccc}
\hline \multirow{2}{*}{ Time (h) } & $\mathbf{p H}$ & \multicolumn{6}{c}{ TP concentration $(\boldsymbol{\mu g} / \mathbf{m L})$} \\
\cline { 3 - 7 } & & $\mathbf{0}$ & $\mathbf{5}$ & $\mathbf{1 0}$ & $\mathbf{2 0}$ & $\mathbf{5 0}$ \\
\hline \multirow{3}{*}{24} & 6.6 & $47.71 \pm 0.01$ & $47.34 \pm 0.02$ & $46.04 \pm 0.01$ & $45.42 \pm 0.03$ & $40.25 \pm 0.02$ \\
& 6.8 & $47.79 \pm 0.02$ & $46.42 \pm 0.03$ & $45.96 \pm 0.01$ & $44.79 \pm 0.02$ & $44.58 \pm 0.02$ \\
& 7.2 & $54.58 \pm 0.00$ & $52.85 \pm 0.02$ & $49.17 \pm 0.02$ & $46.42 \pm 0.01$ & $45.88 \pm 0.02$ \\
\hline
\end{tabular}

VEGF: vascular endothelial growth factor; TP: triptolide; Values are mean $\pm S D(n=3)$

Table 3: Content of VEGF-C (ug/ml) at different TP concentrations and $\mathrm{pH}$ values

\begin{tabular}{lcccccc}
\hline \multirow{2}{*}{ Time (h) } & $\mathbf{p H}$ & \multicolumn{5}{c}{ TP concentration $(\boldsymbol{\mu g} / \mathbf{m L})$} \\
\cline { 2 - 6 } & 6.6 & $172.77 \pm 0.01$ & $\mathbf{0}$ & $\mathbf{1 0}$ & $\mathbf{2 0}$ & $\mathbf{5 0}$ \\
\hline \multirow{2}{*}{24} & 6.8 & $179.79 \pm 0.01$ & $175.21 \pm 0.01$ & $174.47 \pm 0.03$ & $173.92 \pm 0.02$ & $170.00 \pm 0.02$ \\
& 7.2 & $181.60 \pm 0.02$ & $180.43 \pm 0.04$ & $178.75 \pm 0.01$ & $178.51 \pm 0.02$ & $175.43 \pm 0.02$ \\
\hline \multicolumn{2}{l}{ VEGF = vascular endothelial growth factor; $T P=$ triptolide; values are mean $\pm S D(n=3)$}
\end{tabular}


Acid conditions may contribute to cell death and necrosis within solid tumors. Many cells, however, are known to survive under marginal conditions, and these cells may be an important cause for failure of conventional therapies. In the studies of solid tumor, monocyte/macrophage is found to be a type of host cell existing in large quantities [14]. Significant infiltration of the monocyte/macrophages is found in solid tumors such as oral cancer, and was related with the development and metastasis of tumor [15]. Studies have shown that they exist mainly in low oxygen areas with fewer capillaries, which is also corroborated by our studies of oral cancer $[16,17]$.

Monocytes/macrophages have a broad spectrum of biological activities, highly complex and changing phenotypes. They present different phenotypes and functions under the effect of different microenvironment factors, including classically activated macrophages (M1) and alternatively activated macrophages (M2). Recent studies showed that mononuclear macrophages infiltrated in tumor tissues are mainly M2 phenotype [6,7], which can produce enzymes promoting degradation of extracellular matrix and participating in tumor apoptosis and necrocytosis [18]. They can also participate in the process of tumor infiltration, growth and metastasis by secreting many factors that promote vascular and lymphatic growth such as VEGF, VEGF-C [8-10]. It has been suggested that the function of monocytes/macrophages may change the local micro environment of tumor tissues (such as anoxia and acidity), thus decreasing their phagocytosis of tumor cells and strengthening their effect in tumor growth and metastasis [17,19,20]. Monocytes/macrophages also have heterogeneity and play important roles in the biotherapy of tumors $[21,22]$. Therefore, it is of significance to modulate the function of these cells in mildly acid microenvironment in the biotherapy of tumors.

In this study, the number of cells increased with increase in concentration of TP after incubation of monocytes/macrophages with $0-20 \mu \mathrm{g} / \mathrm{mL}$ TP under all $\mathrm{pH}$ values in this study, and the number of cells significantly decreased with $50 \mu \mathrm{g} / \mathrm{mL}$ TP. Cell numbers increased over time during incubation for $24-48 \mathrm{~h}$, but decreased at $72 \mathrm{~h}$. The contents of VEGF and VEGF-C decreased as the TP concentration increased, which suggest that TP can promote proliferation of monocytes/macrophages at a low concentration $(0-20 \mu \mathrm{g} / \mathrm{mL})$ and suppress the proliferation at a high concentration $(50 \mu \mathrm{g} / \mathrm{mL})$. The inhibitory effect of secretion of VEGF and VEGF-C by monocytes/macrophage was enhanced with increase in TP concentration at the same $\mathrm{pH}$, and peaked at $\mathrm{pH}$ 6.6. These results demonstrate that even in mildly acid microenvironment, the proliferation and function of monocytes/macrophages were changed at some level after TP intervention. This may be due to the conversion of the monocytes/ macrophages from tumor-promoting type (M2) to $t$ antitumor type (M1). Under mildly acid microenvironment, TP promotes the proliferation of monocytes/macrophages to some extent and can reduce their ability to secrete tumor growth promoting factors.

\section{CONCLUSION}

The results obtained in this study indicate that the function of monocytes/macrophages can be changed after TP intervention in the mildly acid microenvironment of tumor, thus reducing secretion of tumor growth promoting factors.

\section{ACKNOWLEDGEMENT}

This study was supported by Guizhou Province Science and Technology Department FundGuizhou Province Science and Technology Department United Fund LG no.001 (2011).

\section{REFERENCES}

1. Zamarron BF, Chen W. Dual roles of immune cells and their factors in cancer development and progression. Int J Biol Sci 2011; 7: 651-658.

2. Deng J, Jin J. [Study of triptolide-induced apoptosis in MUTZ-1 cells and its allied mechanism]. Zhongguo Shi Yan Xue Ye Xue Za Zhi 2005; 13: 434-439.

3. Yang S, Chen J, Guo Z, Xu XM, Wang L, Pei XF, Yang J, Underhill CB, Zhang L. Triptolide inhibits the growth and metastasis of tumors. Mol Cancer Ther 2003; 2: 65-72.

4. Ma JX, Sun YL, Wang $Y Q, W u H Y$, Jin J, Yu XF. Triptolide induces apoptosis and inhibits the growth and angiogenesis of human pancreatic cancer cells by downregulating COX-2 and VEGF. Oncol Res 2013; 20: 359-368.

5. Matta $R$, Wang $X$, Ge $H$, Ray $W$, Nelin LD, Liu Y. Triptolide induces anti-inflammatory cellular responses. Am J TransI Res 2009; 1: 267-282.

6. Movahedi K, Laoui D, Gysemans C, Baeten M, Stange G, Van den Bossche J, Mack M, Pipeleers D, In't Veld P, De Baetselier $P$, et al. Different tumor microenvironments contain functionally distinct subsets of macrophages derived from Ly6C (high) monocytes. Cancer Res 2010; 70: 5728-5739.

7. He YF, Zhang MY, Wu X, Sun XJ, Xu T, He QZ, Di, W. High MUC2 Expression in Ovarian Cancer is Inversely Associated with the M1/M2 Ratio of Tumor- 
Associated Macrophages and Patient Survival Time. PLoS One 2013; 8: e79769.

8. Allavena $P$, Sica A, Solinas $G$, Porta $C$, Mantovani A. The inflammatory micro-environment in tumor progression: the role of tumor-associated macrophages. Crit Rev Oncol Hematol 2008; 66: 1-9.

9. Feng $H C$, Song YF, Wen YM. [Correlation between expression of vascular endothelial growth factor- $\mathrm{C}$ in tumor-associated macrophages and lymphatic metastasis in oral cancer]. Ai Zheng 2004; 23: 278281.

10. Obeid E, Nanda R, Fu YX, Olopade OI. The role of tumor-associated macrophages in breast cancer progression (review). Int J Oncol 2013; 43: 5-12.

11. Raghunand $\mathrm{N}, \mathrm{He} X$, van Sluis $R$, Mahoney $B$, Baggett $B$, Taylor CW, Paine-Murrieta G, Roe D, Bhujwalla ZM, Gillies RJ. Enhancement of chemotherapy by manipulation of tumour $\mathrm{pH}$. $\mathrm{Br} J$ Cancer 1999; 80: 1005-1011.

12. Vaupel $P$, Kallinowski $F$, Okunieff $P$. Blood flow, oxygen and nutrient supply, and metabolic microenvironment of human tumors: a review. Cancer Res 1989; 49: 6449-6465.

13. Robey IF, Baggett BK, Kirkpatrick ND, Roe DJ, Dosescu $J$, Sloane BF, Hashim Al, Morse DL, Raghunand N, Gatenby RA, et al. Bicarbonate increases tumor $\mathrm{pH}$ and inhibits spontaneous metastases. Cancer Res 2009; 69: 2260-2268.

14. Collingridge DR, Hill SA, Chaplin DJ. Proportion of infiltrating lgG-binding immune cells predict for tumour hypoxia. Br J Cancer 2001; 84: 626-630.

15. Lee CH, Liu SY, Chou KC, Yeh CT, Shiah SG, Huang RY, Cheng JC, Yen CY, Shieh YS. Tumor-Associated
Macrophages Promote Oral Cancer Progression Through Activation of the AxI Signaling Pathway. Ann Surg Oncol 2014; 21: 1031-1037

16. Feng HC, Song YF. The Spatial Relationship between Tumor-associated Macrophages and Microvessels in Oral Squamous Cell Carcinoma. J Guiyang Med Coll 2003; 28: 12-4.

17. Murdoch C, Giannoudis A, Lewis CE. Mechanisms regulating the recruitment of macrophages into hypoxic areas of tumors and other ischemic tissues. Blood 2004; 104: 2224-2234.

18. Fink K, Boratynski J. [The role of metalloproteinases in modification of extracellular matrix in invasive tumor growth, metastasis and angiogenesis]. Postepy Hig Med Dosw (Online) 2012; 66: 609-628.

19. Song YF, Feng HC, Tang L, Peng JF, Ma $H$. [Experimental study on the anti-tumor effect of monocytes/macrophages against Tca8113 cells and the secretion of vascular endothelial growth factor in acid microenvironment]. Hua Xi Kou Qiang Yi Xue Za Zhi 2010; 28: 364-366.

20. Feng HC, Peng JF, Ma H, Song YF. Experimental study on secretion of VEGF of monocytes/macrophages in hypoxic microenvironment in oral cancer. Chongqing Med 2010; 39: 2244-2245.

21. Liu H, Wu X, Wang S, Deng W, Zan L, Yu S. In vitro repolarized tumor macrophages inhibit gastric tumor growth. Oncol Res 2013; 20: 275-280.

22. De Palma M, Lewis CE. Macrophage regulation of tumor responses to anticancer therapies. Cancer Cell 2013; 23: 277-286. 